Syntax Idea: p-ISSN: 2684-6853 e-ISSN: 2684-883X

Vol. 3, No.10, Oktober 2021

\title{
SISTEM REKOMENDASI JURUSAN PADA SEKOLAH MENENGAH KEJURUAN (SMK) DENGAN ALGORITMA K-MEANS
}

\author{
Siska Howay, Rianto \\ Program Studi Magister Teknologi Informasi, Program Pascasarjana, Universitas \\ Teknologi Yogyakarta, Indonesia \\ Email: siska.howay@student.uty.ac.id, pascasarjana@uty.ac.id
}

\begin{abstract}
Abstrak
Sistem Penentuan jurusan di SMK Negeri 02 Moswaren Kabupaten sorong selatan, merupakan hal yang sangat penting, karena di SMK belum ada sistem penetuan jurusan yang baik sehingga siswa seringkali salah dalam memilih jurusan berdasarkan kemampuan yang dimiliki. Oleh karena itu sistem ini dibuat untuk membantu pihak sekolah dalam menentukan jurusan yang sesuai berdasarkan data nilai rapot, minat, dan bakat. data di ambil dari beberapa angkatan mulai dari angkatan 2019 sampai dengan 2021. Atribut yang dipakai meliputi pemilihan jurusan SMK TKJ, TBSM, TPMG, ATPH, APAT nilai mata pelajaran Penddidikan Agama, PPKN, Bahasa Indonesia, Matematika, IPA, IPS, Penjas, Prakarya, Mulok, Kewira dengan menggunakan dataset 23 data siswa baru. hasil dari pola klasifikasi penentuan jurusan ini dapat digunakan pihak sekolah dalam menentukan kebijakan dalam penentuan jurusan calon siswa pada proses penerimaan peserta didik baru.
\end{abstract}

Kata Kunci: K-Means; rekomendasi; jurusan; SMK

\begin{abstract}
The system of determining majors in SMK Negeri 02 Moswaren South Sorong Regency, is very important, because in SMK there is no good majoring system so students are often wrong in choosing a major based on their abilities. The purpose of this study is to use the recommendation system of majors in vocational high schools (SMK) using the K-Means Algorithm. The research method conducted is to conduct interviews with the school or those responsible at smk to get the data they need. The results of the classification pattern of major determination can be used by the school in determining policies in determining prospective student majors in the admission process of new learners. After conducting this research, it was found that the system had successfully implemented the K-means algorithm to determine the priority of determining vocational expertise programs based on raport junior high school value criteria, interests, student talent.
\end{abstract}

Keywords: K-Means; Recommendation; Department; Vocational High School

$\begin{array}{ll}\text { How to cite: } & \text { Howay. S., \& Rianto. R, (2021) Sistem Rekomendasi Jurusan pada Sekolah Menengah Kejuruan } \\ & \text { (SMK) Dengan Algoritma K-Means, Syntax Idea, 3(10), https://doi.org/10.36418/syntax- } \\ & \text { idea.v3i10.1443 } \\ \text { E-ISSN: } & \text { 2684-883X } \\ \text { Published by: } & \text { Ridwan Institute }\end{array}$




\section{Pendahuluan}

Pendidikan yang berkualitas merupakan harapan dan tuntutan seluruh stakeholder pendidikan. Semua orang tentunya akan lebih suka menntut ilmu pada lembaga yang memiliki mutu yang baik. Atas dasar ini maka sekolah/ lembaga pendidikan harus dapat memberikan pelayanan dan mutu yang baik agar tidak ditinggalkan dan mampu bersaing dengan lembaga Pendidikan lainnya (Ramdhani, 2017).

Pendidikan merupakan suatu sistem yang terbangun dari beberapa komponen pendidikan yang satu dengan yang lain saling berhubungan. Sebagian masyarakat beranggapan bahwa kegagalan dan keberhasilan yang dialami oleh seseorang tergantung pada apa yang mereka dapatkan melalui persekolahan (Fadhli, 2017).

Lembaga pendidikan selalu mengalami perkembangan di sekolah dapat membawa perubahan dilingkungan sekolah tersebut,salah satu aspek budaya sekolah, iklim sekolah, komunikasi, kinerja guru serta peraturan yang ada di dalam sekolah, perkembangan sekolah hendaknya membawa perubahan yang positif terhadap lingkungan sekolah dalam hal ini guru merasa senang dan nyaman di sekolah karena selalu mendapatkan dukungan dari kepala sekolah dari setiap aktivitas yang dilakukan berkaitan dengan mutu pembelajaran di sekolah Gaya kepemimpinan ialah pola- pola perilaku pemimpin yang digunakan untuk mempengaruhi aktivitas orang-orang yang dipimpin untuk mencapai tujuan dalam suatu situasi organisasinya yang dapat berubah (Azizah, Sulianto, \& Cintang, 2018), (Yuningsih \& Herawan, 2015), (Yahya \& Hakim, 2015).

Sekolah menengah kejuruan (SMK) adalah satuan pendidikan formal yang menyelenggarakan pendidikan kejuruan. Pendidikan kejuruan adalah bagian dari pendidikan yang mempersiapkan peserta didik untuk bisa bekerja di bidang tertentu dan mampu bekerja pada suatu kelompok pekerjaan. Maka pada setiap tahun ajaran baru, setiap siswa yang ingin mendaftar di SMK akan memilih jurusan selama belajar di SMK.Tes yang biasa dilakukan pada saat seleksi siswa baru di SMK melalui Nilai rapot SMP, wawancara, dan beberapa hal lainnya (Winangun, 2017).

Proses penentuan jurusan di SMK merupakan hal yang sangat penting, karena nantinya siswa dibekali pembelajaran sesuai dengan jurusan yang telah dipilih secara lebih mendalam dan kedalaman tersebut dimaksudkan sebagai bekal memasuki dunia kerja. Maka dari itu pihak sekolah perlu mengetahui pola minat siswa yang sesuai jurusan yang tersedia untuk menghindari kesalahan dalam pemilihan jurusan. Pola tersebut juga nantinya memudahkan pihak sekolah untuk menentukan jurusan mana yang tepat untuk calon siswa tersebut (Apriliani, 2019).

Sistem rekomendasi adalah suatu sistem yang menyarankan informasi yang berguna atau menduga apa yang akan dilakukan untuk mencapai tujuannya, misalnya seperti memilih jurusan tertentu. Sehingga siswa memilih jurusan dapat lebih efektif dalam menentukan jurusan yang diinginkannya. Metode yang digunakan dalam penelitina ini adalah K-Means (Pradana, 2019).

Proses klasifikasi jurusan sebelumya masi secara manual yaitu menggunakan nilai rapot siswa dan wawancara. Algoritma K-Means dapat membantu untuk menyelesaikan 
sistem penentuan jurusan maka dengan mudah menetukan jurusan yang sesuai kemampuan dari siswa tersebut. hasil klasifikasi dari algoritma K-means memiliki nilai akurasi yang cukup tinggi. Maka dari itu untuk mengetahui pola minat dari siswa-siswi dalam menentukan jurusan yang nantinya akan mereka ambil di SMK digunakan algoritma K-Means (Firza \& Sarjono, 2020).

Tujuan penelitian ini adalah untuk membantu pihak sekolah dalam menentukan jurusan yang sesuai berdasarkan data nilai rapot, minat, dan bakat. data di ambil dari beberapa angkatan mulai dari angkatan 2019 sampai dengan 2021.

\section{Metode Penelitian}

Dalam melakukan penelitian ini, peneliti menggunakan 6 tahapan, yaitu: Ada 6 Tahapan yang dilakukan dalam penelitian ini yaitu: (1.) tahap business understanding, tahapan awal adalah melakukan wawancara dengan pihak sekolah atau yang bertanggung awab di SMK untuk mendapatkan data yang dipeerlukan. Ada beberapa kesalahan yang dilakukan dalam penentuan jurusan, sehingan pihak sekolah masi sulit untuk menetukan jurusan yang cocok untuk calon siswa-siswi di SMK (Rohmad, 2021). (2.) tahap data understanding, data diperoleh dari salah satu Sekolah Menengah Kejuruan data yang di ambil dari beberapa Angkatan angkatan mulai dari 2019 sampai dengan 2021. Atribut yang dipakai meliputi pilihan jurusan I, pilihan jurusan II, jurusan III, jurusan IV, jurusan V, nilai mata pelajaran Penddidikan Agama, PPKN, Bahasa Indonesia, Matematika, IPA, IPS, Penjas, Prakarya, Mulok, Kewira (Handyani, Usmar, $\&$ Walid, 2021). (3.) tahap data preparation, setelah proses pengumpulan data, data ini akan di masukan ke dalam sistem lalu diproses. (4.) tahap modellin, computing approach pada penelitian ini dipilih berdasarkan studi litelatur tentang algoritma KMeans yang mampu mengklasifikasikan pola penjurusan SMK (Irawan, 2017). (5.) analisa dan evaluation pattern, algoritma yang akan diterapkan pada data penjurusan siswa SMK melalui modl simulasi. Dilakukan evaluasi untuk mengamati hasil klasifikasi dari penerapan algoritma K-Means (Hadi, 2019). (6.) Deployment phase. Dari keputusan dihasilkan kemudian diajukan bagi pihak sekolah lalu diterapkan

\section{Hasil dan Pembahasan}

\section{K-Means}

Beberapa teknik klastering yang paling sederhana dan umum adalah klastering K-means. Secara detail teknik ini menggunakan ukuran ketidakmiripan untuk mengelompokan obyek. Ketidakmiripan dapat diterjemahkan dalam konsep jarak. Dua obyek dikatakan mirip jika jarak dua objek tersebut dekat. Semakin tinggi nilai jarak, semakin tinggi nilai ketidakmiripannya. Algoritma klastering K-means dapat diringkas sebagai berikut

1) Pilih jumlah klister

2) Inisialisasi k pusat klaster (diberi nilai-nilai random) 
3) Tempatkan setiap data/obyek ke klaster terdekat. Kedekatan dua obyek ditentukan bersarkan jarak kedua obyek tersebut. Jarak paling dekat antara satu data dengan satu klaster tertentu akan menentukan suatu data masuk dalam klaster mana.

4) Hitung kembali pusat klaster dengan anggota klaster yang sekarang. Pusat klaster adalah rata- rata semua data/obyek dalam klister

5) Tugaskan lagi setiap obyek memakai pusat klaster yang baru. Jika pusat Klaster sudah tidak berubah lagi, maka proses pengklasteran selesai.

Berikut rumus pengukuran jarak :

$$
d_{(x, y)}=\|x-y\|^{2}=\sqrt{\sum_{i=1}^{n}(x i-y i)^{2}}
$$

Keterangan :

$$
\mathrm{d}=\text { titik dokumen; } \mathrm{x}=\text { data record } ; \mathrm{y}=\text { data centroid }
$$

\section{Implementasi K-Means}

Ada beberpa tahapan yang dilakukan untuk mendapatkan keputusan, dalam tahapan ini digunakan algoritma K-Means. Untuk menentukan jurusan yang tepat bagi siswa-siswi di SMK data yang diambil meliputi nilai rapot yang terdiri dari nilai mata pelajaran Penddidikan Agama, PPKN, Bahasa Indonesia, Matematika, IPA, IPS, Penjas, Prakarya, Mulok, Kewira, Minat,Bakat dan Tes Kesehatan dan Tes Olahraga. Sistem dapat melakukan perhitungan nilai siswa agar dapat menentukan program keahlian yang sesuai dengan hasil nilai yang diperoleh (Anita, 2019). Sistem dapat melakukan beberapa pelaporan Laporan siswa yang masuk program keahlian TKJ, TBSM, TPMG, ATPH, APAT. Ada 23 data yang dijdikan sempel data untuk dilakukan proses K-Menas.

\section{Tabel 1}

Nilai rapot 23 siswa

\begin{tabular}{ccccccccccc}
\hline No & Nama & Pa & Pkn & Bhsindo & Mtk & Ipa & Ips & Penjas & Prakarya & Usaha \\
\hline 1 & Aguino & 80 & 75 & 80 & 85 & 80 & 78 & 80 & 75 & 76 \\
\hline 2 & Andreas & 70 & 78 & 78 & 80 & 78 & 75 & 78 & 78 & 78 \\
\hline 3 & MERSI & 80 & 75 & 80 & 85 & 75 & 78 & 77 & 79 & 80 \\
\hline 4 & RILLA & 78 & 79 & 80 & 80 & 78 & 78 & 75 & 80 & 78 \\
\hline 5 & ZULFA & 85 & 78 & 85 & 85 & 78 & 76 & 78 & 77 & 78 \\
\hline 6 & ANDRE & 75 & 77 & 80 & 75 & 76 & 75 & 85 & 76 & 75 \\
\hline 7 & FANO & 85 & 85 & 80 & 85 & 75 & 74 & 85 & 75 & 80 \\
\hline 8 & HELIO & 75 & 77 & 80 & 75 & 74 & 75 & 70 & 69 & 85 \\
\hline 9 & ENJEL & 80 & 75 & 80 & 85 & 75 & 75 & 75 & 70 & 80 \\
\hline 10 & EKA & 85 & 75 & 80 & 80 & 75 & 75 & 75 & 70 & 85 \\
\hline 11 & DIAN & 80 & 75 & 85 & 80 & 75 & 77 & 70 & 70 & 75 \\
\hline 12 & IMERTA & 80 & 80 & 85 & 77 & 79 & 75 & 75 & 76 & 75 \\
\hline 13 & YULI & 80 & 78 & 80 & 75 & 80 & 78 & 85 & 75 & 85 \\
\hline 14 & MARTA & 85 & 85 & 85 & 78 & 77 & 85 & 80 & 74 & 80 \\
\hline 15 & JOSUA & 80 & 75 & 75 & 85 & 76 & 85 & 75 & 75 & 80 \\
\hline 16 & NOVALIN & 80 & 85 & 85 & 85 & 75 & 70 & 85 & 75 & 77 \\
\hline 17 & JEFRY & 80 & 75 & 75 & 70 & 69 & 75 & 75 & 75 & 75 \\
\hline 18 & BAYU & 80 & 80 & 85 & 75 & 70 & 75 & 85 & 79 & 78 \\
\hline
\end{tabular}




\begin{tabular}{ccccccccccc}
\hline No & Nama & Pa & Pkn & Bhsindo & Mtk & Ipa & Ips & Penjas & Prakarya & Usaha \\
\hline 19 & ELSARIO & 80 & 85 & 80 & 75 & 70 & 70 & 75 & 80 & 85 \\
\hline 20 & YANSEN & 85 & 80 & 80 & 70 & 70 & 80 & 75 & 77 & 85 \\
\hline 21 & TIKA & 80 & 75 & 75 & 80 & 80 & 78 & 85 & 76 & 70 \\
\hline 22 & KARISA & 78 & 70 & 80 & 78 & 78 & 76 & 78 & 75 & 75 \\
\hline 23 & IMERTA & 75 & 77 & 80 & 75 & 76 & 75 & 85 & 76 & 75 \\
\hline
\end{tabular}

\section{Perhitungan K-Means}

Proses perhitungan K-Means melibatkan tabel 1. Berdasarkan tabel tersebut, akan diambil nilai rata-rata untuk setiap mata pelajaran, yang kemudian akan ditentukan secara acak untuk menentukan pusat cluster (centroid) awal. Berikut adalah Tabel nilai rata-rata Data nilai rata-rata cluster (centroid).

Tabel 2

Perhitungan K-Means

\begin{tabular}{llllll}
\hline \multicolumn{1}{c}{ MATPEL } & Cluste (0) & Clust (1) & Cluste (2) & Cluste (3) & $\begin{array}{c}\text { Cluste } \\
\text { (4) }\end{array}$ \\
\hline \hline PA & 79.308 & 80.0 & 82.5 & 80.0 & 81.667 \\
\hline \hline PPKN & 75.385 & 76.0 & 83.75 & 80.0 & 80.0 \\
\hline \hline BHSINDO & 79.846 & 80.0 & 82.5 & 82.5 & 78.333 \\
\hline \hline MTK & 82.538 & 77.5 & 82.5 & 76.25 & 71.667 \\
\hline \hline IPA & 76.846 & 74.5 & 73.75 & 78.0 & 69.667 \\
\hline \hline IPS & 77.538 & 75.0 & 73.25 & 78.25 & 75.0 \\
\hline \hline BHS ING & 78.692 & 85.0 & 76.25 & 77.75 & 69.667 \\
\hline \hline SENBU & 73.308 & 80.0 & 81.25 & 79.25 & 81.667 \\
\hline \hline PENJAS & 76.231 & 72.5 & 85.0 & 81.25 & 75.0 \\
\hline \hline PRAKARYA & 74.615 & 69.5 & 76.0 & 75.25 & 77.333 \\
\hline \hline MULOK & 79.923 & 75.0 & 85.0 & 76.25 & 76.667 \\
\hline \hline KEWIRA & 77.308 & 85.0 & 78.75 & 78.75 & 81.667 \\
\hline \hline
\end{tabular}

\section{Jumlah Cluster yang dihasilkan}

Merujuk pada persamaan (1), kemudian dilakukan secara berulang sampai hasil keluaran iterasi menjadi ideal antara cluster0 (c0), cluster1 (c1), cluster2 (c2), cluster3 (c3), cluster4 (c4). Dari hasil keluaran cluster0 adalah jurusan TKJ, cluster1 TBSM, cluster2 TPMG, cluster3 ATPH, cluster4 APAT. Maka jumlah siswa dicluster0 jurusan TKJ 6 orang, cluster1 TBSM 4 siswa, cluster2 TPMG 4 siswa, cluster3 ATPH 7 siswa, cluster4 APAT 2 siswa. Tabel cluster dapat dilihat dibawah ini: 
Siska Howay, Rianto

Tabel 3

Jumlah Cluster dari penelitian

\begin{tabular}{ll}
\hline Cluster 0 & 6 items \\
\hline Cluster 1 & 4 items \\
\hline Cluster 2 & 4 items \\
\hline Cluster 3 & 7 items \\
\hline \hline Cluster 4 & 2 items \\
\hline
\end{tabular}

Total items: 23

\section{Kesimpulan}

Hasil pengujian terhadap "Sistem Rekmendasi penentuan jurusan" ini menunjukkan bahwa sistem telah berhasil mengimplementasikan algoritma K-means untuk menentukan prioritas penentuan program keahlian SMK berdasarkan kriteria nilai Raport SMP, Minat, Bakat Siswa. 
Sistem Rekomendasi Jurusan pada Sekolah Menengah Kejuruan (SMK) dengan Algoritma K-Means

\section{BIBLIOGRAFI}

Anita, Anita. (2019). Pengaruh Facebook Terhadap Prestasi Belajar Siswa Smp Negeri 1 Kikim Tengah Kabupaten Lahat. Uin Raden Fatah Palembang.Google Scholar

Apriliani, Nurul. (2019). Evaluasi Program Praktik Kerja Industri (Prakerin) Jurusan Teknik Komputer Jaringan (TKJ) Di SMK Komputama Jeruklegi Kabupaten Cilacap. IAIN Purwokerto. Google Scholar

Azizah, Mira, Sulianto, Joko, \& Cintang, Nyai. (2018). Analisis keterampilan berpikir kritis Siswa sekolah dasar pada pembelajaran matematika kurikulum 2013. Jurnal Penelitian Pendidikan, 35(1), 61-70. Google Scholar

Fadhli, Muhammad. (2017). Manajemen peningkatan mutu pendidikan. Tadbir: Jurnal Studi Manajemen Pendidikan, 1(2), 215-240. Google Scholar

Firza, Firza, \& Sarjono, Sarjono. (2020). Penerapan Algoritma K-Means Dalam Metode Clustering Untuk Peminatan Jurusan Bagi Siswa Swasta Pelita Raya Kota Jambi. Jurnal Manajemen Sistem Informasi, 5(3), 371-382. Google Scholar

Hadi, Fakhri. (2019). Penerapan Algoritma Cart Dan C4. 5 Untuk Penentuan Jurusan Siswa Baru. Universitas Islam Negeri Sultan Syarif Kasim Riau. Google Scholar

Handyani, Yeni, Usmar, Ali, \& Walid, Abul. (2021). Pengaruh Latar Belakang Pendidikan Dan Gender Terhadap Indeks Prestasi Kumulatif Mahasiswa Tadris Matematika Uin Sulthan Thaha Saifuddin Jambi Angkatan 2017. Uin Sulthan Thaha Saifuddin Jambi. Google Scholar

Irawan, Bei Harira. (2017). Prediksi Kelulusan Tepat Waktu Pada Kampus Stmik Mic Cikarang Dengan Algoritma K-Means Clustering. Jurnal Sigma, 5(1), 10-22. Google Scholar

Pradana, Ferdiansyah Setya. (2019). Analisa dan Perancangan Sistem Informasi Praktek Kerja Industri Menggunakan AHP. JUST IT: Jurnal Sistem Informasi, Teknologi Informasi Dan Komputer, 10(1), 72-77. Google Scholar

Ramdhani, Muhammad Ali. (2017). Lingkungan pendidikan dalam implementasi pendidikan karakter. Jurnal Pendidikan UNIGA, 8(1), 28-37. Google Scholar

Rohmad, Rohmad. (2021). (Lengkapi Lembar Pengesahan Dengan Stempel, Gunakan Ttd Asli Pada Lembar Persetujuan Publikasi, Upload Ulang)... Implementasi Hidden Curriculum Pesantren Untuk Mengembangkan Karakter Religius Siswa Di Smk Sunan Kalijaga Sampung Ponorogo. Iain Ponorogo.

Winangun, Kuntang. (2017). Pendidikan Vokasi Sebagai pondasi bangsa menghadapi globalisasi. Jurnal Taman Vokasi, 5(1), 72-78. Google Scholar

Yahya, Muhammad, \& Hakim, Arif Rahman. (2015). Analisis Pengaruh Gaya 
Siska Howay, Rianto

Kepemimpinan, Motivasi Kerja, dan Kompensasi Terhadap Kinerja Guru (Studi Kasus di SMA PPMI ASSALAM Surakarta). Jurnal Pendidikan Ilmu Sosial, 24(1), 67-77. Google Scholar

Yuningsih, Eri, \& Herawan, Endang. (2015). Kepemimpinan transformasional kepala sekolah dan iklim sekolah terhadap sekolah efektif pada sd negeri di purwakarta. Jurnal Administrasi Pendidikan, 22(2). Google Scholar

Copyright holder:

Siska Howay, Rianto (2021)

First publication right:

Syntax Idea

This article is licensed under:

(c) (i) (O) 